\title{
Combined hydro-wind generation bids in a pool-based electricity market
}

\author{
Jorge L. Angarita ${ }^{a}$, Julio Usaola ${ }^{\mathrm{b}}$, Jorge Martínez-Crespo ${ }^{\mathrm{b}, *}$ \\ a INDRA S.A., Parque Empresarial LA FINCA, edif. 4 y 5 P del Club Deportivo 1, 28223-Pozuelo de Alarcón, Madrid, Spain \\ b Department of Electrical Engineering, Universidad Carlos III de Madrid, Avda. Universidad 30, 28911-Leganés, Madrid, Spain
}

\section{A R T I C L E I N F O}

\section{Article history:}

Received 18 January 2008

Received in revised form 26 August 2008

Accepted 6 January 2009

Available online $\mathrm{xxx}$

\section{Keywords:}

Wind energy

Hydro energy

Stochastic optimization

Electricity markets

Combined bids

\begin{abstract}
A B S T R A C T
Present regulatory trends are promoting the direct participation of wind energy in electricity markets. The final result of these markets sets the production scheduling for the operation time, including a power commitment from the wind generators. However, wind resources are uncertain, and the final power delivered usually differs from the initial power committed. This imbalance produces an overcost in the system, which must be paid by those who produce it, e.g., wind generators among others. As a result, wind farm revenue decreases, but it could increase by allowing wind farms to submit their bids to the markets together with a hydro generating unit, which may easily modify its production according to the expected imbalance. This paper presents a stochastic optimization technique that maximizes the joint profit of hydro and wind generators in a pool-based electricity market, taking into account the uncertainty of wind power prediction.
\end{abstract}

(C) 2009 Elsevier B.V. All rights reserved.

\section{Introduction}

The generation of wind power has increased around the world in recent years. The growth in Europe has been encouraged by the EU Directive 2001/77/EC [1]. The goal of the directive is that $12 \%$ of gross energy consumption in the European Union must be provided by renewable energy sources (RES). In some countries, like Spain, wind power supplies about $10 \%$ of the power demand, although some days in March 2007 reached up to 23\% of the electric demand. Nowadays the wind power installed means 13,606 MW, which accounts for $15 \%$ of the total installed power. This high level of wind energy entails some new technical and financial challenges.

Wind farms have significant difficulties predicting their power output accurately [1-3]. This uncertainty involves energy imbalances with regard to the power committed in pool-based electricity markets, and these imbalances usually result in financial penalties [4-6]. One way to reduce the expected imbalance cost is to use a stochastic optimization tool. Taking into account the penalties due to imbalances, this kind of tool allows optimal wind energy to be traded on the market [7]. Another method for reducing the expected imbalance cost is to work together with other types of generating units, like a Hydro Generation Company (HGENCO). Some references use a pure hydro system or a hydro generation/pumping system combined with a Wind Generation Company (WGENCO) to provide the committed power in the electric power system

\footnotetext{
* Corresponding author. Tel.: +34 91 6249948; fax: +34 916249430. E-mail addresses: jlangarita@indra.es (J.L. Angarita), jusaola@ing.uc3m.es (J. Usaola), jorgemar@ing.uc3m.es (J. Martínez-Crespo).
}

[8-13]. In these cases, the aim is to find the optimal hydro or hydro/pumping operation in order to provide a reliable energy supply. This strategy is useful in small or isolated systems. In [14,15], a wind and pumping ensemble system is considered in a deregulated market. In both research papers, starting from a deterministic and well-known wind generation forecasting, hydro generation and pumped water are found. This algorithm is enhanced in [16], where the expected wind generation is considered as a stochastic parameter. Several simulations using the Monte Carlo method are carried out for different values of wind generation.

In this paper, the imbalances are treated differently. In a deregulated market, the WGENCO-HGENCO ensemble (WH-GENCO) tries to maximize its own profit. Thus, the company reduces imbalances only if it increases this profit. In that case, the market incentive to avoid imbalances will be defined by the penalty price of imbalances.

The problem is set for Spanish market rules, although they are not followed exactly. The Spanish electricity market is a pool-based market where all market players must present their bids for a whole day at 10:00 AM of the previous day. The accepted bids program entails a power commitment for the whole day $(24 \mathrm{~h})$. This market is called daily market. This commitment may be modified six times a day, every $4 \mathrm{~h}$, in the intraday markets, buying or selling energy by means of bids submitted $3 \mathrm{~h}$ before the operation time. Finally, if there are differences between the last accepted bid of a market player and its actual production, the system overcost due to this mismatch between generation and demand must be paid by those agents who incur it, in accordance with the amount of this deviation. It involves a decrease in the revenue of these agents (wind generators are usually found among them). Under this regulatory framework, two alternative strategies could be followed: 
- Combined operation strategy: Once the WGENCO and HGENCO energy is traded on the electricity market, both companies have a committed power. Nevertheless, in real time (about $1 \mathrm{~h}$ ahead) and starting from the current generated wind power, the WGENCO can calculate with small uncertainty the imbalances for the energy committed in the next hour. With that information, at this time, the HGENCO may change its own generation in order to obtain the maximum profit for the WH-GENCO ensemble. Thus, the HGENCO will move its generation towards the optimal values to reduce the wind power imbalances whenever this action increases the combined profit. Finally, notice that if the HGENCO traded all its rated power in the pool market, it could not support the WGENCO position.

- Combined bidding strategy: In this case, depending on the energy to be traded on the electricity market, the HGENCO plans its power reserve and, consequently, its availability to reduce imbalances caused by wind power. In accordance with the plan, the decision is taken considering the expected wind power distribution probability, which is a stochastic variable. It should be noted that this bid design strategy sets the optimal energy to be submitted to the market with the aim of obtaining the maximum profit for the WH-GENCO joint optimal operation (previous item), but with the bid defined hours before instead of in real time. That is, the combined bids design strategy has a higher hierarchical decision level than the operation planning.

In this paper, the authors follow this last novel strategy. The WHGENCO ensemble will be considered a price-taker and a detailed hydro model is used. The proposed algorithm is a mixed-integer $(0 / 1)$ linear problem which has been solved under GAMS mathematical modelling language using the solver CPLEX 9.0 [17].

This paper is organized as follows. Considerations about the wind power forecast and hydro system are shown in Sections 2 and 3, respectively. Section 4 formulates the mathematical model for defining the combined bid. Section 5 provides an application example, comparing the results with other possible ways to decide how energy is traded. Finally, conclusions are stated in Section 6.

\section{Uncertainty of wind prediction}

In power systems with a high percentage of wind power, shortterm wind power forecast has become a technique used for system operation and for submitting bids in electricity markets whenever wind generators are allowed to make bids. Prediction tools use numerical weather forecasts and one of them also uses real time SCADA data from the wind farms. Starting from these inputs and by means of physical and/or statistical models, hourly predictions for a time horizon of about $48 \mathrm{~h}$ are provided. The accuracy of these prediction tools is assessed through the Normalized Mean Absolute Error $\left(\mathrm{NMAE}_{t}\right)$, defined as shown in (1), where predictions have been made $t$ hours before operation time, $N$ being the number of predictions considered.

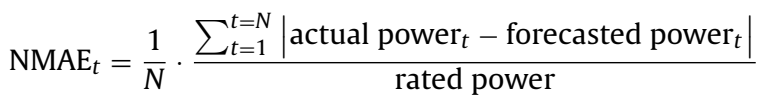

Fig. 1 shows average values of this parameter. Two main features can be observed: first, the higher the time elapsed between prediction and operation is, the higher the forecasting error; second, the error decreases when the forecasting process is done for an ensemble and also decreases with the size of the ensemble. Similar conclusions can be found in [1] and [2]. The results shown in Fig. 1 have been obtained with SIPREÓLICO, the short-term wind power prediction tool running in Red Eléctrica de España (the Spanish TSO) and developed by Universidad Carlos III de Madrid. This pro-

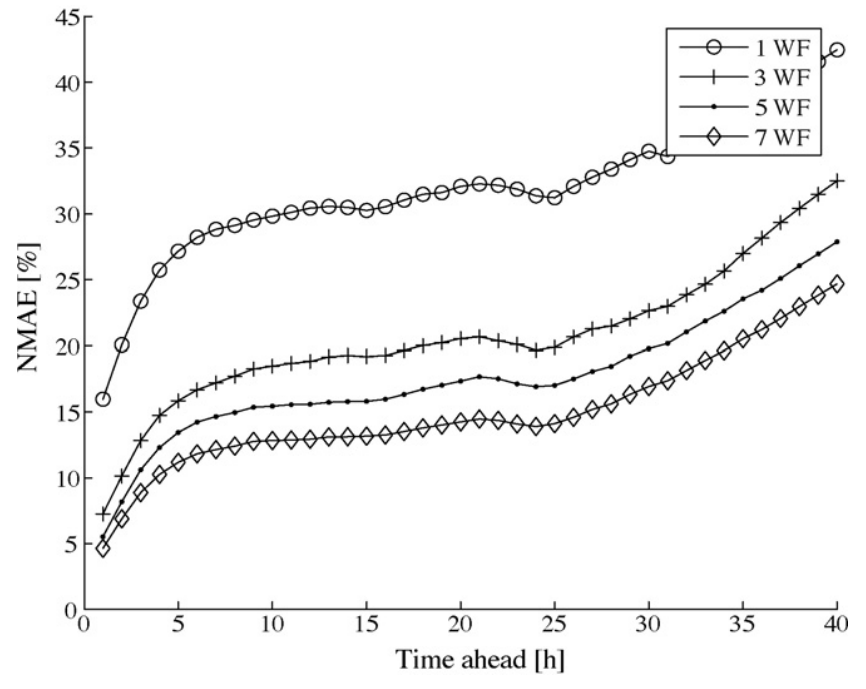

Fig. 1. NMAE for different wind farm ensembles.

gram provides predictions every 15 min for more than 11,000 MW of wind power connected to the Spanish peninsular power system [5].

In general, the quality of a prediction depends mainly on two variables, the time between prediction and operation and the forecasting technique. Another important prediction factor is the forecasting process, which has no important bias. Therefore, in general, the probability of over/under prediction might be considered equal.

In this document, the hourly wind power output is considered a stochastic variable with a known discrete density function (DDF). The set of values for the DDF at time $t$ is $\Omega_{t}=$ $\left\{e w p_{t}^{1}, e w p_{t}^{2}, \ldots, e w p_{t}^{N_{t}}\right\}$ with probability $\left\{\rho_{t}^{1}, \rho_{t}^{2}, \ldots, \rho_{t}^{N_{t}}\right\}[18]$. This hourly information is necessary for calculating the overall time outcomes. Every overall-period outcome is a set that has a possible wind generation value for every hour. This study considers all the hourly sets $\Omega_{t}$ to contain $N$ possible outcomes, i.e., $\left|\Omega_{t}\right|=$ $N_{t}=N \quad \forall t$. Under this consideration, the set $\Omega$, which represents the total number of outcomes for the whole time horizon, will contain $W=\prod_{t=1}^{t=T}\left|\Omega_{t}\right|=\prod_{t=1}^{t=T} N=N^{T}$ elements. The probability $\rho_{w}$ of every outcome $w$ is defined by multiplying the probabilities associated with every possible hourly power output in the overallperiod outcomes.

\section{Hydro model}

The aim of the short-term hydro scheduling model is to determine the optimal generation programming for every plant in the river basin. The hydro model is considerably more complex than the wind model.

The input-output hydro generation function describes the relationship between discharged water and generated power. This relationship is strongly non-linear but it can be represented through a concave piecewise linearization [19-21], as shown in Fig. 2. A polynomial approximation is considered in Ref. [22], and finally, other Refs. $[23,24]$ use a non-concave piecewise linearization.

Fig. 2 draws the relation between power and water discharge for a hydro plant $i$. This relationship has been represented in this paper by a piecewise linear approximation with 4 blocks. Every piece has its own slope and water discharge limit.

The hydro model considered in this paper is based on the model proposed in [24]. 


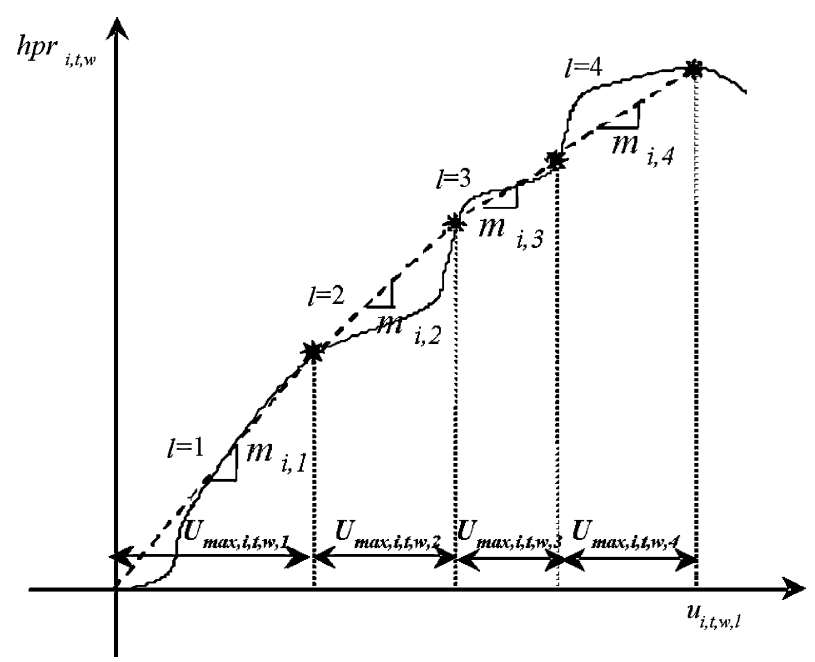

Fig. 2. Concave piecewise linearization.

\section{Mathematical model for the combined bid}

As stated earlier, from an economic point of view, the imbalance cost reduction problem may be separated into two complementary strategies, the combined operation strategy and the combined bidding strategy. The following equations represent the modeling for the second one. This strategy consists of calculating the optimal combined hourly energy, $h w p d_{t}$. The output of the combined bid will be used later in the operation stage. Therefore, the model decides the optimal power to be traded, calculating its expected profit for every wind outcome. The objective function to maximize is:

$E H W P=\sum_{t=1}^{t=T} \sum_{w=1}^{w=W} \rho_{w} \cdot\left\{E H P_{t, w}+E H R_{t, w}-E P_{t, w}\right\}$

subject to:

$E H P_{t, w}=\sum_{i=1}^{i=I}\left\{\lambda_{t} \cdot h p r_{i, t, w}-s c_{i} \cdot y_{t, i, w}+Q_{i, w}\right\} \quad \forall t \in T, \forall w \in W$

$h p r_{i, t, w}=\sum_{l=1}^{l=L} m_{i, l} \cdot u_{i, t, l, w} \quad \forall i \in I, \forall t \in T, \forall w \in W$

$x_{i, t, w}=x_{i, t-1, w}+W_{i, t}+M \cdot \sum_{h \in \Omega i} \sum_{l=1}^{l=L}\left\{u_{h, t-\tau i h, l, w}+s_{h, t-\tau i h, l, w}\right\}$

$-M \cdot \sum_{l=1}^{l=L}\left\{u_{i, t, l, w}+s_{i, t, l, w}\right\} \quad \forall i \in I, \forall t \in T, \forall w \in W$

$\bar{X}_{i} \geq x_{i, t, w} \geq \underline{X}_{i} \quad \forall i \in I, \forall t \in T, \forall w \in W$

$\max \left\{\underline{U}_{i}, \underline{U}_{i, t}^{e x t}\right\} \leq \sum_{l=1}^{l=L} u_{i, t, l, w} \leq \min \left\{\bar{U}_{i,} \bar{U}_{i, t}^{\text {ext }}\right\}$

$\forall i \in I, \forall t \in T, \forall w \in W$

$u_{i, t, l, w} \leq \bar{U}_{i, l} \cdot \mu_{t, i, w} \quad \forall i \in I, \forall t \in T, \forall l \in L, \forall w \in W$

$$
\begin{aligned}
& Q_{i, w}=\sum_{j \in \Theta i}^{j=I}\left\{x_{i, T F, w} \cdot \overline{m_{j}} \cdot \frac{\gamma}{M}\right\} \quad \forall i \in I, \forall w \in W \\
& y_{t, i, w}-z_{t, i, w}=\mu_{t, i, w}-\mu_{t-1, i, w} \quad \forall i \in I, \forall t \in T, \forall w \in W \\
& E W R_{t, w}=e w p_{t, w} \cdot \lambda_{t} \quad \forall t \in T, \forall w \in W \\
& E P_{t, w}=R_{t, w} \cdot \lambda_{t} \cdot \psi_{t} \quad \forall t \in T, \forall w \in W
\end{aligned}
$$$$
\psi_{t}=\left\{\begin{array}{c}
\psi_{t, \text { up }} \text { if }\left[\sum_{i=1}^{i=I}\left\{h p r_{i, t, w}\right\}+e w p_{t, w}-h w p d_{t}\right]>0 \\
\psi_{t, \text { down }} \text { if }\left[\sum_{i=1}^{i=I}\left\{h p r_{i, t, w}\right\}+e w p_{t, w}-h w p d_{t}\right]<0
\end{array}\right\}
$$

It should be noted that time periods of $1 \mathrm{~h}$ are considered, so $x$ MW is equivalent to $x$ MWh and a water discharge $k$ represents a change of $k / M \mathrm{Hm}^{3}$ in the volume.

Notice also that the problem aims to find the optimal power that provides the maximum expected revenue for a joint optimal operation.

Eq. (2) shows the objective function to be maximized. The profit is calculated as the revenue for the energy produced by both companies, HGENCO and WGENCO, minus the penalties due to the energy deviations. Eq. (3) sets the HGENCO profit: the revenue due to the produced energy plus the future revenue because of stored water in the reservoir minus start-up costs. It should also be remarked that the hydro generation model sets a certain water price at the end of the time horizon as a constraint. On the contrary, other references set limits on the final volume [13]. Eq. (4) defines the piecewise linear hydro generation model. The temporal continuity of the hydro reservoir level is formulated as (5). Constraint (6) sets the lower and upper limits on the reservoir level. Constraint (7) fixes the limits on the discharge for every plant; these limits may come from either technical constraints on the power plant discharge or external constraints like environmental considerations, navigability conditions, fishing constraints, etc. Constraint (8) sets the upper discharge limit of each block of the piecewise linear curve. Eq. (9) models the future value of the stored water in the reservoirs. Eq. (10) sets a logical relation between power plant start-up, shut-down and on-line status. Eq. (11) defines the expected profit for the WH-GENCO. Finally, the expected penalty in the operation is modeled in (12) and (13).

The optimal bid maximizes the weighted-probability profit for each overall-period outcome. For every possible wind outcome, the WH-GENCO ensemble decides the best hydro generation. A hydro power generation different from its optimal value (a value obtained when the HGENCO operates individually) always carries a reduction of the profit for the HGENCO. Therefore, the HGENCO will only support the wind power deviations if the reduction of the hydro profit is lower than the avoided wind penalty. In the present model, we know exactly what the energy trade price and the penalty prices are.

The optimization problem for defining HGENCO generation is constrained by giving a value to the water remaining at the end of time horizon $Q_{i, w}$. As is stated in [25], in general, a hydro power station $i$ will consume water using only those blocks that satisfy the following equation:

$\lambda_{t} \cdot m_{i, l} \geq \gamma \cdot \overline{m_{i}}$

Eq. (14) states that the HGENCO spills water only when the revenue due to the power generated is higher than the future revenue of storing it. As the Hill Chart is a piecewise linearization, Eq. (14) is only fulfilled up to a certain block $l$ of that piecewise linearization, 


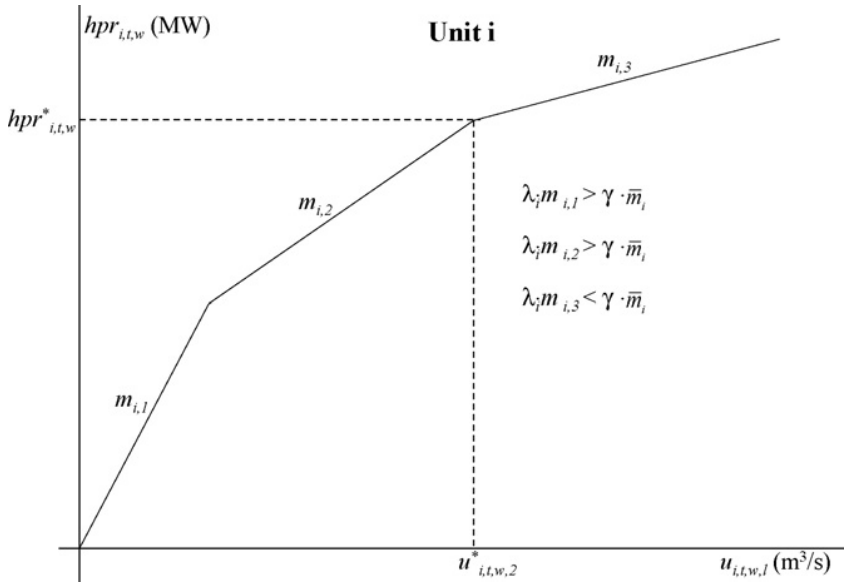

Fig. 3. Optimal hydro schedule for time $t$.

but it is not valid for the next ones. The necessary conditions for defining the optimal hydro power bid $h p r_{i, t, w}^{*}$ are shown in Fig. 3 for a three-block linearization. In a general way, a hydro plant $i$ fulfills that:

$\lambda_{t} \cdot m_{i, l}>\gamma \cdot \overline{m_{i}} \quad \forall l<k$

$\lambda_{t} \cdot m_{i, l}<\gamma \cdot \overline{m_{i}} \quad \forall l>k$

For example, in Fig. 3, blocks 1 and 2 satisfy Eq. (14) but block 3 does not fulfil it. In this particular case, index $k$ would be equal to 2 in Eqs. (15) and (16).

At time $t$, if for a scenario $w$ the wind generation is low (producing less than expected), hydro power plant $i$ can increase its power output in a quantity $\Delta h p r_{i, t, w}$ to compensate totally or partially for the wind deviation. This action reduces the combined imbalances and therefore lets the agents decrease their penalties $\Delta E P_{t, w}$, as shown in (17).

$$
\begin{aligned}
\Delta E P_{t, w} & =\psi_{t, \text { down }} \cdot \lambda_{t} \cdot \Delta h p r_{i, t, w} \\
& =\sum_{l=k+1}^{l=L} \psi_{t, \text { down }} \cdot \lambda_{t} \cdot \Delta u_{t, i, l, w} \cdot m_{i, l} \quad \forall t \in T, \forall w \in W
\end{aligned}
$$

This change in the hydro power output implies less water at the end of the period and therefore a reduction in the future income (see (18)).

$\Delta B_{t, w, \text { future }}=-\sum_{l=k+1}^{l=L} \overline{m_{i}} \cdot \gamma \cdot \Delta u_{i, t, l, w} \quad \forall t \in T, \forall w \in W$

Nevertheless, the additional hydro generation $\Delta h p r_{i, t, w}$ results in additional income in the market.

$$
\begin{aligned}
\Delta B_{t, w, \text { current }} & =\lambda_{t} \cdot \Delta h p r_{i, t, w} \\
& =\sum_{l=k+1}^{l=L} \lambda_{t} \cdot \Delta u_{i, t, l, w} \cdot m_{i, l} \quad \forall t \in T, \forall w \in W
\end{aligned}
$$

The net variation in the combined profit due to additional hydro generation is illustrated in Eq. (20).

$\Delta$ profit $_{t, w}=\Delta E P_{t, w}+\Delta B_{t, w, \text { future }}+\Delta B_{t, w, \text { current }} \quad \forall t \in T, \forall w \in W$

Only if $\Delta$ profit $_{t, w}$ is higher than zero, the HGENCO will compensate for the shortage of wind production by increasing the water consumed to generate more electric power. Under this consideration, $\Delta$ profit $_{t, w}>0$, and substituting Eqs. (17), (18) and (19) in (20), it is possible to get Eq. (21).

$\lambda_{t} \cdot\left(1+\psi_{t, \text { down }}\right) \cdot \sum_{l=k+1}^{l=L}\left(\Delta u_{i, t, l, w} \cdot m_{i, l}\right)>\overline{m_{i}} \cdot \gamma \cdot \sum_{l=k+1}^{l=L} \Delta u_{i, t, l, w}$

Eq. (21) gives useful information. For example, returning to the case shown in Fig. 3, Eq. (21) would become:

$m_{i, 3} \cdot \lambda_{t} \cdot\left(1+\psi_{t, \text { down }}\right)>\overline{m_{i}} \cdot \gamma$

Comparing Eqs. (16) and (22), it is easy to realize that the penalty factor $\psi_{t, \text { down }}$ makes it more attractive to consume water in block 3 when the wind generation is short. Notice that once Eq. (22) is satisfied, using block 3 for compensating for any wind power deviation is profitable. If the piecewise linearization was made using few blocks and/or the rated power of the hydro plant is very large compared with the rated wind generation, that is to say, if the power of each block is very big, once Eq. (22) is satisfied, all short wind deviation will be compensated for.

A similar procedure can be followed for long wind positions. Eq. (23) will be valid in that case.

$m_{i, 2} \cdot\left(\lambda_{t}-\psi_{t, \text { up }}\right)<\overline{m_{i}} \cdot \gamma$

As will be verified in next section, this analysis explains why the hydro unit will not respond to certain values of $\psi_{t \text {,down }}$ and $\psi_{t \text {,up }}$, and however, once those penalties get over a certain value, all the deviations are compensated for.

\section{Test system and results}

Participation of wind energy into electricity markets is not possible in all the countries, and, the participation rules vary widely and change relatively quick. In order to give an insight of the possibilities of the proposed method, an example has been run following loosely the Spanish market rules, which allow the joint participation of wind energy, but not a joint bid between wind and hydro greater than $50 \mathrm{MW}$. The conclusions presented here could be extrapolated to other systems and rules, although different balance management systems (for instance) could have a strong impact on the numerical results.

\subsection{Time period}

In the example, the scheduling horizon is composed of five periods $(T=5)$, each being $1 \mathrm{~h}$ long. This time is similar to the operation time that corresponds to a Spanish intraday market.

\subsection{Hydro generation data}

The HGENCO considered in this test system has eight reservoirs linked between them. The example has been taken from [24].

Table 1 illustrates three items of the test system: maximum water discharge for every plant, the slope of every block, and maximum power output.

Hourly power output shown in Table 2 is obtained when the HGENCO submits a bid considering only its own revenue [24]. It will be useful to compare these data with the results of this combined model. Hourly prices (see last row of Table 2 ) correspond to average prices in the Spanish daily market.

\subsection{Wind generation data}

The rated power of the wind farm is $250 \mathrm{MW}$. For stochastic wind power generation, every hour contains three different generation 
Table 1

Blocks slope and water discharge limits.

\begin{tabular}{|c|c|c|c|c|c|c|}
\hline \multirow[t]{2}{*}{ Plant } & \multicolumn{4}{|c|}{ Slope $\left[\mathrm{MW} / \mathrm{m}^{3} / \mathrm{s}\right.$ ] } & \multirow{2}{*}{$\begin{array}{l}\text { Umax }\left[\mathrm{m}^{3} / \mathrm{s}\right] \\
\text { All blocks }\end{array}$} & \multirow[t]{2}{*}{ Maximal power output [MW] } \\
\hline & Block 1 & Block 2 & Block 3 & Block 4 & & \\
\hline Plant 1 & 0.9 & 0.85 & 0.83 & 0.78 & 15.0 & 50.4 \\
\hline Plant 2 & 0.75 & 0.73 & 0.7 & 0.67 & 39.5 & 112.6 \\
\hline Plant 3 & 0.7 & 0.65 & 0.63 & 0.6 & 112.5 & 290.3 \\
\hline Plant 4 & 0.82 & 0.8 & 0.77 & 0.75 & 160.8 & 504.8 \\
\hline Plant 5 & 0.85 & 0.82 & 0.8 & 0.75 & 152.5 & 491.1 \\
\hline Plant 6 & 0.78 & 0.73 & 0.7 & 0.68 & 116.3 & 336.0 \\
\hline Plant 7 & 0.75 & 0.72 & 0.7 & 0.66 & 239.0 & 676.4 \\
\hline Plant 8 & 0.8 & 0.76 & 0.74 & 0.72 & 249.5 & 753.5 \\
\hline
\end{tabular}

Table 2

Power schedule (MW) and hourly price (\$/MWH).

\begin{tabular}{|c|c|c|c|c|c|}
\hline \multirow[t]{2}{*}{ Plants } & \multicolumn{5}{|c|}{ Generation schedule for all the plants [MW] } \\
\hline & Hour 1 & Hour 2 & Hour 3 & Hour 4 & Hour 5 \\
\hline Plant 1 & 26.25 & 38.7 & 0 & 38.7 & 50.4 \\
\hline Plant 2 & 58.46 & 86.11 & 0 & 86.11 & 112.57 \\
\hline Plant 3 & 151.88 & 222.75 & 0 & 222.75 & 290.25 \\
\hline Plant 4 & 260.41 & 384.19 & 0 & 504.76 & 504.76 \\
\hline Plant 5 & 254.68 & 376.68 & 0 & 376.68 & 491.05 \\
\hline Plant 6 & 175.54 & 256.91 & 0 & 256.91 & 335.96 \\
\hline Plant 7 & 351.33 & 518.63 & 0 & 518.63 & 676.37 \\
\hline Plant 8 & 389.22 & 573.85 & 0 & 753.49 & 753.49 \\
\hline Total & 1667.77 & 2457.82 & 0 & 2758.03 & 3214.85 \\
\hline Price [\$/MWh] & 60 & 62 & 48 & 63 & 66 \\
\hline
\end{tabular}

scenarios, $\left|\Omega_{t}\right|=3 \quad \forall t$. Therefore, the total number of outcomes for the scheduling horizon are $W=\prod_{t=1}^{t=5}\left|\Omega_{t}\right|=243$.

Table 3 shows hourly wind power values and their probabilities. Two different bid strategies can be used depending on the wind power offered: the highest probability wind power value (HPWPV strategy) or the expected wind power value (EWPV strategy).

The highest probability wind power value (HPWPV) and the expected wind power value (EWPV) are calculated using hourly expected wind power values $\left(e w p_{t}^{n}\right)$. The HPWPV, in column 7, is the highest probability wind power value for every hour (see (24)). $e w p_{t}^{H P}=\left\{e w p_{t}^{k} \mid \rho_{t}^{k} \geq \rho_{t}^{n} \quad \forall n \in N_{t}: k \in N_{t}\right\}$

The EWPV shown in column 6 is calculated using (25).

$e w p_{t}^{E}=\sum_{n=1}^{n=N_{t}} \rho_{t}^{n} \cdot e w p_{t}^{n}$

The expected deviations, columns 8-11 of Table 3 , are calculated as is shown in (26) and (27), where $e w p_{t}^{*}$ takes the values $e w p_{t}^{H P}$ or $e w p_{t}^{E}$ depending on the expected deviation from what is being calculated in the optimization process.

Expected deviation $_{t}$ (down)

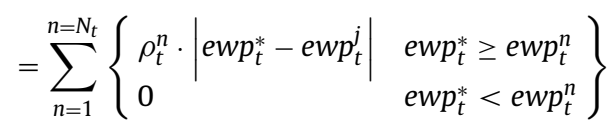

Expected deviation $_{t}$ (up)

$$
=\sum_{n=1}^{n=N_{t}}\left\{\begin{array}{cl}
\rho_{t}^{n} \cdot\left|e w p_{t}^{*}-e w p_{t}^{n}\right| & e w p_{t}^{*} \leq e w p_{t}^{n} \\
0 & e w p_{t}^{*}>e w p_{t}^{n}
\end{array}\right\}
$$

The total wind expected deviations are shown in the last row of Table 3. They are $53.7(26.85+26.85)$ and $53.5(42.5+11) \mathrm{MW}$ for EWPV and HPWPV, respectively. According to (1), these deviations mean a NMAE value of $4.3 \%$ for both cases. The wind data used represent a realistic situation for an ensem-

Table 3

\begin{tabular}{|c|c|c|c|c|c|c|c|c|c|c|}
\hline \multirow[t]{3}{*}{ Time } & \multirow[t]{3}{*}{ Power and probability } & \multicolumn{3}{|c|}{ Outcomes } & \multirow[t]{3}{*}{ EWPV } & \multirow[t]{3}{*}{ HPWPV } & \multicolumn{4}{|c|}{ Expected deviation } \\
\hline & & \multirow[t]{2}{*}{1} & \multirow[t]{2}{*}{2} & \multirow[t]{2}{*}{3} & & & \multicolumn{2}{|c|}{ Using EWPV } & \multicolumn{2}{|c|}{ Using HPWPV } \\
\hline & & & & & & & Down & Up & Down & Up \\
\hline Hour 1 & $\begin{array}{l}\text { Power [MW] } \\
\text { Probability }\end{array}$ & $\begin{array}{r}230 \\
0.3\end{array}$ & $\begin{array}{r}200 \\
0.5\end{array}$ & $\begin{array}{l}190 \\
0.2\end{array}$ & 207 & 200 & 6.90 & 6.90 & 2.00 & 9.00 \\
\hline Hour 2 & $\begin{array}{l}\text { Power [MW] } \\
\text { Probability }\end{array}$ & $\begin{array}{r}250 \\
0.4\end{array}$ & $\begin{array}{r}235 \\
0.3\end{array}$ & $\begin{array}{r}220 \\
0.3\end{array}$ & 236.5 & 250 & 5.40 & 5.40 & 13.50 & 0.00 \\
\hline Hour 3 & $\begin{array}{l}\text { Power [MW] } \\
\text { Probability }\end{array}$ & $\begin{array}{r}230 \\
0.2\end{array}$ & $\begin{array}{r}220 \\
0.45\end{array}$ & $\begin{array}{r}200 \\
0.35\end{array}$ & 215 & 220 & 5.25 & 5.25 & 7.00 & 2.00 \\
\hline Hour 4 & $\begin{array}{l}\text { Power [MW] } \\
\text { Probability }\end{array}$ & $\begin{array}{r}210 \\
0.45\end{array}$ & $\begin{array}{r}190 \\
0.35\end{array}$ & $\begin{array}{l}175 \\
0.2\end{array}$ & 196 & 210 & 6.30 & 6.30 & 14.00 & 0.00 \\
\hline Hour 5 & $\begin{array}{l}\text { Power [MW] } \\
\text { Probability }\end{array}$ & $\begin{array}{r}190 \\
0.5\end{array}$ & $\begin{array}{l}180 \\
0.4\end{array}$ & $\begin{array}{l}170 \\
0.1\end{array}$ & 184 & 190 & 3.00 & 3.00 & 6.00 & 0.00 \\
\hline Total & & & & & 1038.5 & 1070 & 26.85 & 26.85 & 42.50 & 11.00 \\
\hline
\end{tabular}

Wind power outcomes. 
ble of 5 wind power farms for which forecasts are made $1 \mathrm{~h}$ in advance.

\subsection{Results}

With the previous data, the WH-GENCO ensemble must make the combined bid. In this example case, the penalties $\psi_{t \text {,up }}, \psi_{t \text {,down }}$ considered for the study will have the same value, i.e., $\psi_{t \text {, up }}=$ $\psi_{t, \text { down }}=\psi \quad \forall t$.

The agents have many options for defining their bids, but the two most natural ones would be the following: (1) a first strategy would use the expected wind power value (EWPVS) and (2) a different strategy would use the highest probability wind power value (HPWPVS). In each case, the combined bid would be defined by the $e w p_{t}^{E}$ and $e w p_{t}^{H P}$, respectively, plus the optimal hydro power, and the traded power would be fixed regardless of the value of the penalties $\psi_{t \text {,down }}, \psi_{t \text {,up. }}$. Consequently, these strategies cannot ensure the best bid, as they do not consider the penalties. The main disadvantage of these strategies is that they do not take into account keeping enough reserve for all the wind deviations. In this paper, the results of these two strategies will be compared with the optimal bid resulting from the mathematical model presented in this paper.

Table 4 compares powers committed considering the algorithm proposed in (2)-(13) with the results obtained via the expected wind power value strategy (EWPVS) and the highest probability wind power value strategy (HPWPVS).

Table 4 shows that when the penalty increases, the HGENCO compensates for all the wind energy deviations and, therefore, these wind deviations will be taken into account in the energy committed in the market. Analyzing the table results, if the optimal hydro bid is the maximum value $(h=5: 3215 \mathrm{MW})$, the optimal value for the combined bid must be the lowest expected wind power value plus the maximum hydro power output (e.g., $3215+170=3385 \mathrm{MW}$ ). Therefore, if the wind generation for the operation period is the minimum value, the hydro plant must generate its maximum power, and if the wind power in the operation is higher than the minimum expected value, the hydro power plant will decrease its generation from the maximum to a value where the power deviation is zero. This case is fulfilled for a penalty greater than or equal to $20 \%$ of the market clearing price $(\psi=0.2)$. On the contrary, for $\psi=0.1$, the penalty is too low, and the HGENCO bid will not compensate for any downward wind power deviation (short position).

When the optimal hydro bid is zero $(h=3,0 \mathrm{MW})$, the optimal combined bid is the maximum expected wind generation (e.g., for $h=3,230 \mathrm{MW}$ ). Consequently, if the wind generation is the maximum expected value, the hydro generation is zero, and if the wind generation is lower than its maximum value, the hydro power plant will generate the power value necessary to get a null deviation. This situation takes place for a penalty equal to or greater than $70 \%$ of the market clearing price $(\psi=0.7)$. For lower penalties, the com- bined bid will not cover all the possible wind positions. Notice that for these cases the combined bid was $220 \mathrm{MW}$; therefore if the wind generation was $230 \mathrm{MW}$, the hydro power plant could not compensate for this over-generation, since hydro power is shut down and it cannot reduce its production. In the other strategies (EWPVS and HPWPVS), the declared power did not keep enough reserve to follow wind deviations regardless of the penalty values.

Whenever the optimal hydro bid is zero, compensating for down-wind power deviation implies the start-up of the unit and, therefore, the HGENCO will lose the opportunity cost and will have to pay the start-up cost. Here the opportunity cost means either the spillage of water, when the best financial option is to save it to be sold in the future, or vice versa. In the study case, it occurs for $\psi=0.7$.

If the optimal hydro power is maximum, compensating for upwind power deviations entails decreasing the hydro power from the maximum value, and it implies losing the opportunity cost. In the study case, this happens for $\psi=0.1$.

Table 5 shows the expected deviations and the cost of these deviations for the algorithm proposed as well as for the other alternative strategies (EWPVS and HPWPVS). The total deviation represents the power deviation accumulated throughout the possible scenarios, weighted by the probability of each scenario, for the 5-h scheduling horizon. It should be noted that deviations using alternative strategies cannot cover the deviations because they do not have enough reserve for this situation even if the price is high.

For example, if the HPWPVS strategy is analyzed, there is an updeviation (long position) of $2 \mathrm{MW}$ that is not covered (see first row of HPWPVS block in Table 5). In this case, when the power committed is $220 \mathrm{MW}$ and the actual wind generation is $230 \mathrm{MW}$, there is no possibility of compensating for the deviation of $10 \mathrm{MW}$. This situation has a probability of 0.2 ; that is, the expected deviation is then 10.0.2 $=2 \mathrm{MW}$. Notice that up-deviations cannot be covered only in hour 3. In contrast, hour 5 represents the opposite case. For the strategy HPWPVS, the combined power bid is $3405 \mathrm{MW}$ (see Table 4). Since the maximum hydro power generation is $3215 \mathrm{MW}$, wind generation values lower than $190 \mathrm{MW}$ cannot be covered. In this case, two different wind power generations can be found. The first one is $180 \mathrm{MW}$, which carries a down-deviation of $10 \mathrm{MW}$ with probability 0.4 , that is, $4 \mathrm{MW}$ of expected down deviation. In the second one, the wind generation is $170 \mathrm{MW}$, which implies a downdeviation of $20 \mathrm{MW}$ with probability 0.1 , that is to say, $2 \mathrm{MW}$ of expected down deviation. Therefore, the total expected down deviation is equal to $6 \mathrm{MW}$ (see data in Table 3 and results in second row of HPWPV block in Table 5).

\subsection{Benefits of the combined bid}

The benefit of using the proposed algorithm (delta wind profit, $d w p$ ) compared to the alternative strategies is evaluated as shown

Table 4

Combined power bid.

\begin{tabular}{|c|c|c|c|c|c|c|c|c|c|c|c|c|c|}
\hline \multirow[t]{3}{*}{ Period } & \multirow{3}{*}{$\begin{array}{l}\text { Optimal hydro } \\
\text { bid [MW] }\end{array}$} & \multirow{3}{*}{$\begin{array}{l}\text { Using EWPV } \\
{[\mathrm{MW}]}\end{array}$} & \multirow{3}{*}{$\begin{array}{l}\text { Using HPWPV } \\
{[\mathrm{MW}]}\end{array}$} & \multicolumn{10}{|c|}{ Optimal combined power bid [MW] } \\
\hline & & & & \multicolumn{10}{|c|}{$\psi_{t, \text { up }}=\psi_{t, \text { down }}$} \\
\hline & & & & 0.1 & 0.2 & 0.3 & 0.4 & 0.5 & 0.6 & 0.7 & 0.8 & 0.9 & 1 \\
\hline Hour 1 & 1667.8 & 1874.8 & 1867.8 & 1867.8 & 1867.8 & 1867.8 & 1867.8 & 1867.8 & 1867.8 & 1867.8 & 1867.8 & 1867.8 & 1867.8 \\
\hline Hour 2 & 2457.8 & 2694.3 & 2707.8 & 2677.8 & 2677.8 & 2677.8 & 2677.8 & 2677.8 & 2677.8 & 2677.8 & 2677.8 & 2677.8 & 2677.8 \\
\hline Hour 3 & 0.0 & 215.0 & 220.0 & 220.0 & 220.0 & 220.0 & 220.0 & 220.0 & 220.0 & 230.0 & 230.0 & 230.0 & 230.0 \\
\hline Hour 4 & 2758.0 & 2954.0 & 2968.0 & 2933.0 & 2933.0 & 2933.0 & 2933.0 & 2933.0 & 2933.0 & 2933.0 & 2933.0 & 2933.0 & 2933.0 \\
\hline Hour 5 & 3214.9 & 3398.9 & 3404.9 & 3394.8 & 3384.8 & 3384.8 & 3384.8 & 3384.8 & 3384.8 & 3384.8 & 3384.8 & 3384.8 & 3384.8 \\
\hline
\end{tabular}


Table 5

Deviation for different penalties and strategies.

\begin{tabular}{|c|c|c|c|c|c|c|c|c|c|c|}
\hline \multirow[t]{2}{*}{ Penalty [market price times] } & \multicolumn{10}{|c|}{$\psi_{t, \text { up }}=\psi_{t, \text { down }}$} \\
\hline & 0.1 & 0.2 & 0.3 & 0.4 & 0.5 & 0.6 & 0.7 & 0.8 & 0.9 & 1 \\
\hline \multicolumn{11}{|l|}{ Optimal combined bid } \\
\hline down_deviation [MW] & 8.0 & 0.0 & 0.0 & 0.0 & 0.0 & 0.0 & 0.0 & 0.0 & 0.0 & 0.0 \\
\hline cost_up_dev $[€]$ & 9.6 & 19.2 & 28.8 & 38.4 & 48.0 & 57.6 & 0.0 & 0.0 & 0.0 & 0.0 \\
\hline cost_down_dev $[€]$ & 40.2 & 0.0 & 0.0 & 0.0 & 0.0 & 0.0 & 0.0 & 0.0 & 0.0 & 0.0 \\
\hline total_cost_dev $[€]$ & 49.8 & 19.2 & 28.8 & 38.4 & 48.0 & 57.6 & 0.0 & 0.0 & 0.0 & 0.0 \\
\hline \multicolumn{11}{|c|}{ High probability wind power value } \\
\hline up_deviation [MW] & 2.0 & 2.0 & 2.0 & 2.0 & 2.0 & 2.0 & 2.0 & 2.0 & 2.0 & 2.0 \\
\hline down_deviation [MW] & 13.0 & 6.0 & 6.0 & 6.0 & 6.0 & 6.0 & 6.0 & 6.0 & 6.0 & 6.0 \\
\hline cost_up_dev $[€]$ & 9.6 & 19.2 & 28.8 & 38.4 & 48.0 & 57.6 & 67.2 & 76.8 & 86.4 & 96.0 \\
\hline cost_down_dev $[€]$ & 73.2 & 79.2 & 118.8 & 158.4 & 198.0 & 237.6 & 277.1 & 316.7 & 356.3 & 395.9 \\
\hline total_cost_dev [€] & 82.8 & 98.4 & 147.6 & 196.8 & 246.0 & 295.2 & 344.3 & 393.5 & 442.7 & 491.9 \\
\hline \multicolumn{11}{|l|}{ Expected wind power value } \\
\hline up_deviation [MW] & 5.3 & 5.3 & 5.3 & 5.3 & 5.3 & 5.3 & 5.3 & 5.3 & 5.3 & 5.3 \\
\hline down_deviation [MW] & 8.3 & 3.0 & 3.0 & 3.0 & 3.0 & 3.0 & 3.0 & 3.0 & 3.0 & 3.0 \\
\hline cost_up_dev $[€]$ & 25.2 & 50.4 & 75.6 & 100.8 & 126.0 & 151.2 & 176.4 & 201.6 & 226.8 & 252.0 \\
\hline cost_down_dev $[€]$ & 45.0 & 39.6 & 59.4 & 79.2 & 99.0 & 118.8 & 138.5 & 158.3 & 178.1 & 197.9 \\
\hline total_cost_dev [€] & 70.2 & 90.0 & 135.0 & 180.0 & 225.0 & 270.0 & 314.9 & 359.9 & 404.9 & 449.9 \\
\hline
\end{tabular}

in (28).

$d w p=\frac{H W E P(O P T)-H W E P(E W P V S \text { or HPWPVS })}{\sum_{t=1}^{t=T} \sum_{w=1}^{w=W} \rho_{w} \cdot E P_{t, w}(E W P V S \text { or HPWPVS })} \cdot 100$

The numerator of (28) is the expected profit through the proposed algorithm minus the expected profit using one of the two alternative strategies. The denominator of (28) is the expected penalty of the optimal operation subject to the power declared using the deterministic (alternative) strategies. Fig. 4 shows the $d w p$ values for the proposed algorithm and for HPWPVS under different price considerations. A different line chart is depicted for different values of the Normalized Mean Absolute Error (NMAE). A higher NMAE implies a greater advantage in using the proposed model (compared with the deterministic strategy).

Using Fig. 4 and Fig. 1, a WH-GENCO agent might calculate the benefit of the algorithm proposed here. For example, if the Spanish pool-based market is analyzed, when the energy is traded in intradaily sessions, the time between the bid time and the real operation ranges from 4 to $7 \mathrm{~h}$. Therefore, using data from Fig. 1, the NMAE is about $25-30 \%$ for a single wind farm [25]. Though deviation penalties $\psi_{t \text {,up }}, \psi_{t \text {,down }}$ in the Spanish case are difficult to predict, the Ref. [26] states penalties around $27 \%$ of the market price, $\psi=0.27$. With these values, as Fig. 4 shows, the $d w p$ is around $30-35 \%$. In general, the benefits depend on penalties, how long in advance the forecast is made, the size of ensemble and hydro model features. According to the results shown in Fig. 4, savings range from 15\% to $45 \%$ using the algorithm proposed instead of the alternative strategies.

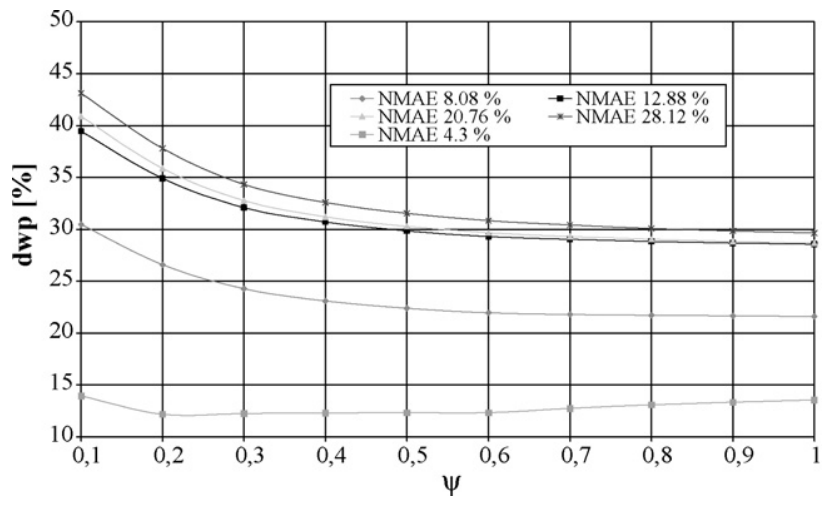

Fig. 4. Change in the wind profit for different wind average deviation.

\section{Conclusion}

The possibility of combining hydro and wind energy, and its profitability for market participants to make joint bids has been shown in the present paper. This profitability depends on the capacity of the hydro reservoir and on the imbalance cost. Low imbalance costs, which reflect the cost of the imbalance reserves, decreases the interest of this joint bid.

In the paper, wind generation is considered a stochastic parameter and the input-output hydro generation function is represented through a concave piecewise linearization. The optimal combined bid is calculated simulating the optimal future operation for all possible wind outcomes. The proposed model has been tested for realistic forecasting conditions as well as different penalties due to imbalances applied to an ensemble of a HGENCO with eight reservoirs linked among them and a WGENCO of $250 \mathrm{MW}$ rated power. A 5-h scheduling horizon (similar period to the operation time of a Spanish intraday market) has been used.

The algorithm has been compared to other possible bid strategies that make use of the highest probability wind power value (HPWPV strategy) or the expected wind power value (EWPV strategy). It has been checked that when the penalty increases, the HGENCO compensates for all the wind energy deviations and, therefore, these wind deviations will be taken into account in the energy committed in the market. On the contrary, if the penalty is too low $(\psi=0.1)$, the HGENCO bid will not compensate for any wind power deviation.

The combined bidding strategy obtains significant improvements regarding the other bid strategies mentioned. These improvements are shown through the $d w p$ (delta wind profit), which is evaluated for different values of the Normalized Mean Absolute Error (NMAE). The results show that between 15\% and 45\% of the penalties can be saved using the algorithm proposed. Thus, considering a realistic NMAE around $25-30 \%$ for a single wind farm and using penalties around $27 \%$ of the market price (case of the Spanish pool-based market), the $d w p$ would be around $30-35 \%$.

In short, this paper shows that the combined hydro-wind bid strategy is a very useful tool for the generating agents in order to avoid penalty costs or income reduction. The final benefits will depend on penalty values, how long in advance the wind forecast is made and the size of ensemble and hydro model features.

As a future line of research, it could be studied the effect of this possibility of joint hydro/wind bids on the overall system reserves management. 


\section{Acknowledgments}

This research has been carried out within the project "Estrategias competitivas de ofertas de energías renovables en un entorno liberalizado. Aplicación al caso español. DPI2003-00862", supported by the Spanish Ministry of Science and Technology.

\section{Appendix A. List of symbols}

\section{Constants}

$m_{i, l} \quad$ Slope of block $l$ of plant $i$ in the hydro unit performance curve UPC $\left[\mathrm{MW} / \mathrm{m}^{3} / \mathrm{s}\right]$

$\bar{m}_{j} \quad$ Average slope of plant $i$ in the hydro unit performance curve UPC $\left[\mathrm{MW} / \mathrm{m}^{3} / \mathrm{s}\right]$

M Conversion factor, from water discharged to volume, equals $3.6 \times 10^{-3}\left[\mathrm{Hm}^{3} \mathrm{~s} / \mathrm{m}^{3}\right]$

$\bar{U}_{i, l} \quad$ Maximum water discharge of block $l$ of plant $i\left[\mathrm{~m}^{3} / \mathrm{s}\right]$

$\bar{U}_{i} \quad$ Maximum water discharge of plant $i$ due to technical constraints $\left[\mathrm{m}^{3} / \mathrm{s}\right]$

$\underline{U}_{i} \quad$ Minimum water discharge of plant $i$ due to technical constraints $\left[\mathrm{m}^{3} / \mathrm{s}\right]$

$\bar{U}_{i, t}^{\text {ext }} \quad$ Maximum water discharge of plant $i$ in period $t$ due to external constraints $\left[\mathrm{m}^{3} / \mathrm{s}\right]$

$\underline{U}_{i, t}^{\text {ext }} \quad$ Minimum water discharge of plant $i$ in period $t$ due to external constraints $\left[\mathrm{m}^{3} / \mathrm{s}\right]$

$\bar{X}_{i} \quad$ Maximum content of the reservoir associated with plant $i\left[\mathrm{Hm}^{3}\right]$

$\underline{X}_{i} \quad$ Minimum content of the reservoir associated with plant $i$ $\left[\mathrm{Hm}^{3}\right]$

$W_{i, t} \quad$ Forecasted natural water inflow of the reservoir associated with plant $i$ in period $t\left[\mathrm{Hm}^{3} / \mathrm{h}\right]$

$\lambda_{t} \quad$ Forecasted energy price in period $t[€ / \mathrm{MWh}]$

$\tau_{i j} \quad$ Time required so that the water flows from reservoir $j$ to reservoir $i[\mathrm{~h}]$

$\psi_{t, \text { down }}$ Penalty for down deviation, as a percentage of market price in hour $t$

$\psi_{t \text {,up }} \quad$ Penalty for up deviation, as a percentage of market price in hour $t$

$\gamma \quad$ Future value of the stored water $\left[€ / \mathrm{Hm}^{3}\right]$

$s c_{i} \quad$ Start cost of plant $i[€]$

\section{Variables}

EHWP $\quad$ Expected hydro-wind profit $[€]$

$E H P_{t, w} \quad$ Expected hydro profit in period $t$ associated with outcome $w[€]$

$E W R_{t, w} \quad$ Expected wind revenue in period $t$ for outcome $w[€]$

$E P_{t, w} \quad$ Expected penalty for the power deviation in period $t$ associated with outcome $w[€]$

$h p r_{i, t, w}$ Hydro power generated by plant $i$ in period $t$ associated with outcome $w[\mathrm{MW}]$

$Q_{i, w} \quad$ Future value of the stored water in the reservoirs associated with plant $i$ and outcome $w\left[€ / \mathrm{Hm}^{3}\right]$

$R_{t, w} \quad$ Power imbalance in period $t$ for outcome $w$ [MW]

$s_{i, t, w} \quad$ Spillage of the reservoir associated with plant $i$ in period $t$ for outcome $w\left[\mathrm{~m}^{3} / \mathrm{s}\right]$

$u_{i, t, l, w} \quad$ Water discharge of plant $i$ in period $t$ for block $l$ associated with outcome $w\left[\mathrm{~m}^{3} / \mathrm{s}\right]$

$x_{i, t, w} \quad$ Content of the water reservoir of plant $i$ in period $t$ associated with outcome $w\left[\mathrm{Hm}^{3}\right]$

$x_{i, T F, w} \quad$ Content of the water reservoir of plant $i$ for outcome $w$ and at the end of the scheduling period $\left[\mathrm{Hm}^{3}\right]$

$y_{t, i, w} \quad$ Binary variable equals 1 if plant $i$ is started at the beginning of period $t$ $z_{t, i, w} \quad$ Binary variable equals 1 if plant $i$ is shut down at the beginning of period $t$

$\mu_{t, i, w} \quad$ Binary variable equals 1 if plant $i$ is on-line at the beginning of period $t$

$h w p d_{t} \quad$ Hydro-wind power declared in the bid for period $t$ [MW] The types of the other variables can be deduced from the variables defined in this list $u_{i, t, l, w}, s_{i, t, w} \geq 0 \quad \forall i \in I, \forall t \in T, \forall l \in L, \forall w \in W$; $y_{i, t, w}, z_{i, t, w}, \mu_{i, t, w} \in\{0,1\} \quad \forall i \in I, \forall t \in T, \forall w \in W$

Stochastic outcomes

ewp $p_{t, w}$ Wind power value in period $t$ associated with outcome $w$ [MW]

$e w p_{t}^{n} \quad$ One of the possible values of the expected wind power during period $t$ [MW]

$\rho_{w} \quad$ Probability for outcome $w$

Sets

I Set of indices of the plants belonging to the same river basin and the same company

$L \quad$ Set of indices of blocks of piecewise linearization of the unit performance curve

$T \quad$ Set of indices of the periods of the market time horizon

$\Theta_{i} \quad$ Set of power plants downstream from plant $i$

$\Omega_{i} \quad$ Set of power plants immediately upstream from plant $i$

\section{References}

[1] European Parliament, Directive 2001/77/EC of the European Parliament and of the Council of 27 September 2001: on the promotion of electricity produced from renewable energy sources in the internal electricity market, Official Journal of the European Communities, vol. L283/33.

[2] M.C. Alexiadis, P.S. Dokopoulos, H.S. Sahsamanoglou, I.M. Manousaridis, Shortterm forecasting of wind speed and relaxed electrical power, Solar Energy 63 (1) (1998) 61-68.

[3] U. Focken, M. Lange, K. Mönnich, H. Waldl, H.G. Beyer, A. Luig, Short-term prediction of aggregated power output of wind farms-a statistical analysis of the reduction of the prediction error by spatial smoothing effects, J. Wind Energy Eng. Ind. Aerodyn. 90 (2002) 231-246.

[4] I. Sánchez, Short-term prediction of wind energy production, Int. J. Forecasting 22 (2006) 43-56.

[5] Spanish Electricity Market Activity Rules (English version) [online]. Available: http://www.omel.es.

[6] The Office of Gas and Electricity Markets (OFGEM). An Overview of the New Electrical Trading Arrangement [online]. Available: http://www.ofgem.gov.uk.

[7] The Common Nordic Power Market (Nordpool). Available: http://www.nordpool.com

[8] G.N. Bathurst, J. Weatherrill, G. Strbac, Trading wind generation in short-term energy markets, IEEE Trans. Power Syst. 17 (3) (2002) 782-789.

[9] S. Galloway, G. Bell, G. Burt, J. McDonald, T. Siewierski, Managing the risk of trading wind energy in a competitive market, IEE Proc.-Gener. Transm. Distrib. 153 (1) (2006) 106-114.

[10] O.A. Jaramillo, M.A. Borja, J.M. Huacuz, Using hydropower to complement wind energy: a hybrid system to provide firm power, Renewable Energy 29 (11) (2004) 1887-1909.

[11] C. Bélanger, L. Gagnon, Adding wind energy to hydro power, Energy Policy 30 (14) (2002) 1279-1284.

[12] J.K. Kaldellis, K.A. Kavadias, Optimal wind-hydro solution for Aegean Sea islands' electricity demand fulfillment, J. Appl. Energy 70 (4) (2001) 333-354.

[13] C. Bueno, J.A. Carta, Wind powered pumped hydro storage systems, and mean of increasing the penetration of renewable energy in the Canary Islands, Renew. Sustain. Energy Rev. 10 (4) (2006) 312-340.

[14] E.D. Castronuovo, J.A. Peças Lopes, Optimal operation and hydro storage sizing of a wind-hydro power plant, Electr. Power Energy Syst. 26(10)(2004) 771-778.

[15] E.D. Castronuovo, J.A. Peças Lopes, Bounding active power generation of a windhydro power plant, in: Proceedings of the 8th International Conference on Probabilistic Methods Applied to Power Systems, Iowa State University, Ames, Iowa, 2004.

[16] E.D. Castronuovo, J.A. Peças Lopes, On the optimization of the daily operation of a wind-hydro power plant, IEEE Trans. Power Syst. 19 (3) (2004) 1599-1606.

[17] CPLEX 10.0 Users Manual. Available: http://www.gams.com.

[18] G. Infanger, DECIS User's Guide: A System for Solving Large-scale Stochastic Programs. Available: http://www.gams.com/docs/DECIS-Users_Guide.pdf.

[19] G.W. Chang, C.T. Su, A practical mixed integer linear programming based on short-term hydro scheduling, in: Proceedings of the IEEE/PES Transmission and Distribution Conference and Exhibition 2002, vol. 3, Asia Pacific, October 2002, pp. $1606-1610$ 
[20] G.W. Chang, M. Aganagic, J.G. Waight, J. Medina, T. Burton, S. Reeves, M. Christoforidis, Experiences with mixed integer linear programming based approaches on short-term hydro scheduling, IEEE Trans. Power Syst. 16 (4) (2001) 743-749.

[21] G.X. Luo, H. Habibollahzadeh, A. Semlyem, Short-term hydro-thermal dispatch detailed model and solutions, IEEE Trans. Power Syst. 4 (4) (1989) 1452-1462.

[22] H. Brännlund, D. Sjelvgren, J.A. Bubenko, Short-term generation scheduling with security constraints, IEEE Trans. Power Syst. 3 (1) (1988) 310-316.

[23] O. Nilson, D. Sjelvgren, Variable splitting applied to modeling of start-costs in short-term hydro generation scheduling, IEEE Trans. Power Syst. 12 (2) (1997) 770-775.

[24] A. Conejo, J.M. Arroyo, J. Contreras, Self-scheduling of a hydro producer in a pool-based electricity market, IEEE Trans. Power Syst. 17 (4)(2002) 1265-1272.

[25] J. Angarita, Integración de energía eólica en mercados competitivos de energía eléctrica, PhD thesis, Universidad Carlos III de Madrid, 2007.

[26] J. Parkes, J. Wasey, A. Tendal, L. Muñoz, Wind energy trading benefits through short-term forecasting. Available: http://www.garradhassan. com/downloads/reports.

Jorge Luis Angarita-Márquez obtained his B.S. degree and his M.Sc. at Universidad Industrial de Santander in 1997 and 2000, respectively, and his Ph.D. from Universidad Carlos III de Madrid in 2007.
He is currently working as a consultant for Indra S.A., Madrid, Spain. His research interests include power systems planning, wind energy systems, distribution systems as well as optimization.

Julio Usaola García received his B.S. degree and his Ph.D. degree in Electrical Engineering from E.T.S. de Ingenieros Industriales de Madrid in 1986 and 1990, respectively.

In 1988 he joined the Department of Electrical Engineering in E.T.S. de Ingenieros Industriales de Madrid where he remained until 1994. He is currently a professor in the Department of Electrical Engineering at the Universidad Carlos III de Madrid. His research interests are centered on grid integration of wind energy systems and electricity markets.

Jorge Martínez Crespo received his B.S, degree in power engineering from E.T.S. de Ingenieros Industriales de Madrid in 1995 and his Ph.D. degree in electrical engineering from Universidad Carlos III de Madrid in 2004.

In 1998 he joined the Department of Electrical Engineering in the Universidad Carlos III de Madrid. He is working as an assistant professor in the Department of Electrical Engineering at the Universidad Carlos III de Madrid. His research interests include grid integration of wind energy systems, and power systems operation, planning and optimization. 